\title{
Energy Scenario and Diversity in Pakistan: An Energy Security Perspective
}

\author{
Ruqqaya Safeer ${ }^{1}$, Dr. Noor Fatima ${ }^{2, *}$ \\ ${ }^{1}$ MPhil Researcher, Department of International Relations and Political Science, International Islamic University, Pakistan \\ ${ }^{2}$ Assistant Professor, Department of International Relations and Political Science, International Islamic University, Pakistan
}

Copyright $\odot 2019$ by authors, all rights reserved. Authors agree that this article remains permanently open access under the terms of the Creative Commons Attribution License 4.0 International License

\begin{abstract}
Energy being the lifeline for socio economic development has become the leading issue of 21st century. There is global increase in demand of energy and it will continue to increase due to immoderate energy consumption. Today there is global fear of energy crisis as world primary demand of energy is expected to rise about 1.7 percent annually in next twenty years. South Asia is expected to give largest share for increase in global energy demand. Pakistan being a developing state is facing acute energy crisis that has hampered the socio-economic development. The energy crisis of Pakistan and its spillover effects on efficiency of other sectors especially economic sector has created serious issues in Pakistan for the last two decades. The overreliance on imported energy resources to satisfy the demand and less emphasis on the development of domestic energy resources is deteriorating the socio-economic conditions of country. There are two major sources of energy being used in Pakistan, renewable and non-renewable sources. In Pakistan, there has been more focus on non-renewable sources of energy which are largely acquired through imports of oil to satisfy the increasing demand. The state Energy policy has somehow has not able to match with the increasing energy demand and therefore citizens angered by frequent power outages demonstrate to protests and riots. Thus, this article, accentuate on the need of the utilization of the indigenous resources of energy to fulfill the energy need and to eradicate the acute crisis of energy. this research will also assess the issues in Power policy and Power sector institutions of Pakistan.
\end{abstract}

Keywords Energy, Pakistan, Indigenous Resources, Renewable Energy, Non-renewable Energy, Energy Mix, Diversification

\section{Introduction}

Energy security has become the top priority issue around the globe. The increasing quest and worldwide increasing demand of energy has made energy an important strategic reserve. The global depletion of conventional energy resources with every tick of clock and increasing energy demand round the clock compelled the world to opt for alternative methods of energy production. Therefore, globally there is intensifying trend towards diversification of traditional energy mix. The Hubert hypothesis of peak oil and energy inclusion in UN sustainable development goals further alarmed the nations to renew their energy resources. Peak oil is the assumed point where world fossil fuel production predominantly oil will follow downward trend where world would be left with very rare fossil resources. [1] It imbued the nations to seek alternative sources of energy for sustainable development. Though hundred percent conversions from conventional to unconventional sources of energy is not a matter of day it will take time. However, some countries unexpectedly had shown very swift movement in diversification of their energy mix.

Pakistan being a developing state is facing acute energy crisis that has hampered the socio-economic development. In Pakistan there is very slow development towards adopting alternative sources of energy. Pakistan despite having enough resource endowments is facing unprecedented energy crisis that is lingering day by day. This severe energy crisis and its domino effect on economic sector is leading country towards anomalous economic recession. The Socio-economic issues attached with this crisis are demanding Pakistan to speedily diversify its energy mix. Presently, Pakistan is heavily dependent on imported sources of energy for satisfying most of its energy need. There is instant need to expedite diversification process otherwise Pakistan will remain far behind in world of rapidly growing economies.

The lack of sectoral cohesiveness and interest has failed to formulate integrated policy with vision and intellect of whole energy sector. Each sub -sector working under energy sector is pursuing different policy that come out with unbalanced energy mix and overreliance on imports. 
Despite of indigenously available coal and hydro potential country heavily relies on imported oil and gas imports for power generation. It shows lack of cohesion among different ministries especially among WAPDA and NCA as well as Ministry of energy. [2]

The ignorance factor further delays any progress and leads to seek short term solutions for recurring energy shortfalls rather than bringing pragmatic solutions for controlling energy deficit. Moreover, the financial issues and insufficient research capability also hinders in bringing alternative sources of energy to satisfy growing demand of energy. Thus, the focus of this research is to investigate the root causes of Pakistan's energy crisis keeping in view the issues in energy sector, policy making and implementation process. The question addressed in this research is Why Pakistan is facing unprecedented energy crisis despite having indigenous potential to fulfill the energy demand? How the policy and sectoral ineptness is responsible for Pakistan's energy deficiency? The research also endeavors to suggest certain policy options for the future energy policy of Pakistan to satisfy the energy demand.

\section{Literature Review}

The issues of Pakistan energy sector can be divided in to three categories; it includes policy related issues, issues in governance, financial issues and technical issues. The fragmented structure of the sector and lack of collaboration between various entities is a serious issue. This issue affects the institutional working and smooth implementation of policies. [3] Pakistan electricity sector is facing the issues of poor governance, Ineffective planning and political influence in policy decisions. [4]

Pakistan energy crisis is more of a governance issue than supply, inefficiencies in governance, problems of circular debts, losses of T\&D, electricity theft and poor management are not due to supply shortage but indication of governance inefficiency. Energy crisis is not limited to energy sector only but it creates serious consequences for other sectors as well, from industry to economy, every sector is being affected by energy crisis. Now energy has got prominent space in election campaigning and used by Pakistani politicians as political slogan in their speeches. [5]

From 1960 onwards numerous energy plans were given by the government of Pakistan, though proper policy document was given in 1994 to fulfill the growing demand of energy. From 1990s onward number of policies announced but major flaw in all these policy documents was the lack of integration and ignorance toward utilizing tools of modeling e.g. ENPEP, BALANCE, LEAP, MARKAL/TIMES. These tools are very helpful in policy planning and are used widely around the globe. [6]

There is no integrated energy policy in Pakistan as there are separate policy documents for renewable policy, power
Policy, petroleum policy. Though policy formulation is not an easy job. The Policy has to consider the stakeholder interest as well as to take care of those who can't defend themselves. [7] Pakistan needs a well-integrated policy to overcome the crisis of energy. There are more political slogans and less policy actions and outcomes that fulfill the energy demand of population. Political slogans can please people for only short period ultimately this is proper policy planning and implementation that works. [8]

Pakistan have indigenous options available for overcoming energy crisis but these options have been ignored by policy planners from about three decades. There is need of integration and harmonization of policy governance to overcome this lingering energy crisis. [9] Energy sector need a well-planned and clearly articulated policy for the development. There has been no effort made in history to devise an integrated policy of energy. There are number of piece-meal policies introduced in country, however these policies were nor effective neither capable for bringing energy security in the country.[10]

Although Pakistan energy crisis is chronic and need long term planning, but energy demand can also be mitigated by taking some short term measures at individual level through responsible use of energy at homes, in offices, universities and other sectors. [11] However, Mirza Bergland and Afzal stress more on establishment of energy institution and laws. There is need to incorporate the laws to control the energy consumption and establishing institution that suggest energy conservation methods.

According to an assessment of ENERCON Pakistan has potential to save around 25 percent of energy by responsible use of energy. Furthermore, the energy conservation can save US\$ five billion annually for Pakistan. In this connection, universities and think tanks can also play an effective role in developing the energy conservation culture in Pakistan. IT and Engineering universities can help in technical areas; they can help in building insulation, efficient appliances and by improving boiler technology. A large portion of energy due to technical inefficiencies and transmission losses is being wasted. Engineering institutes can also help in mitigating these line losses. Moreover, engineering universities can help in generation by improving the working of power plants. Social science universities can also play an effective role in promoting energy conservation trend .These universities can start public campaigns to create awareness in masses about energy conservation benefits.Setsudenan energy conservation campaign was launched in Japan for energy conservation that was very successful, Pakistani universities can also start similar sort of movements for developing energy conservation culture in country. Furthermore, think tanks can also play crucial role in energy conservation activity. Think tanks can disseminate the message of energy conservation through their research publications, seminars and conferences. [12] 


\section{Pakistan's Current Energy Scenario}

\subsection{Petroleum Resources/ Oil}

The generation of electricity from petroleum resources has decreased to 5 percent around the globe. [13] However, Pakistan is still heavily reliant on petroleum resources for satisfying its energy demand. Oil constitutes a major share in Pakistan energy mix. Presently oil contributes 33 percent in total energy mix. There is extensive use of oil in power and transport sector of Pakistan. [14]

According to the data provided by global economic indicators the oil consumption of Pakistan has quadrupled from year 1980 to 2014. The oil consumption has reached to 450 thousand barrels per day (2014) from 150 thousand barrel per day (1980). The oil production of Pakistan in FY 2016 has increased by 7.8 percent p.a. It has increased from 65,866 barrels per day to 97,000 barrels per day. [15]

Pakistan's indigenous oil resources are not enough for satisfying oil demand. Therefore, Pakistan seventy percent of oil demand is fulfilled by imports. Most of oil imports are made from Middle Eastern region from worth US dollar 1.84 billion with import of 5.9 million tons of oil. [16] This wide scale import and no export is pushing country toward balance of payment crisis.

\subsection{Natural Gas}

Natural gas is the less polluting and environmental friendly fuel among other fossil fuels. Pakistan energy sector is primarily dominated by gas. The share of natural gas in Pakistan power generation is $31.4 \%$.According to 2014 estimates Pakistan is a major gas consumer country rank twenty third in world with consumption of 39,970,000 thousand cubic meters .[17]The production of gas in Pakistan is around 4.26 billion cubic feet per day.[18]The production of gas has stagnated from last five years .The exploration of approx 10 trillion cubic feet of natural gas during year 1952 in province of Baluchistan at Sui was a huge contribution to Pakistan energy sector. Pakistan was self-sufficient in meeting its gas demand till 2005.Due to large scale utilization of gas in various sectors its demands has increased while supply growth was relatively low. This gap between supply and demand as well as misallocation of gas created shortage of gas in Pakistan.

In 2005 a gas allocation policy was formulated to allocate the gas supply to various sectors in priority order. In policy priority list industry and CNG were fourth preference but both became the largest beneficiaries in year 2005 to 2011.The increased share of gas in other sectors decreased the share of gas in power sector. Diversion of gas to other sector increased the share of expensive imported oil in power sector. [19] The improper implementation and some vested interest failed to implement the formulated plan properly. The failure to properly implement formulated plan and rapid increase in demand instigated gas crisis in Pakistan. To meet the increase demand of gas government of Pakistan has finalized major gas import deals under TAPI and IP projects. These two gas import projects are expected to satisfy the increasing demand of gas consumption.

\subsection{Compressed Natural Gas (CNG)}

Compressed natural gas has wide application as a vehicle fuel globally. Presently almost world 5 million vehicles are using CNG. The use of CNG as vehicular fuel was introduced in Pakistan in 1992. Government of Pakistan encouraged the use of CNG as a vehicular fuel to minimize the use of expensive imported liquid fuel and due to its lower environmental pollution. In world seventy CNG user states Pakistan ranks at no 3 with almost 900,000 vehicles using CNG.[20] But, due to depleting natural gas reserves and its increasing demand in last few years the supply of CNG has been disrupted in country. The disruption in supply resulted in periodic closure of CNG stations and then large queues of vehicles at CNG stations left no option for CNG consumers instead switching to petroleum again.

\subsection{Liquefied Natural Gas (LNG)}

LNG is Conversion of Natural gas in liquefied form for facilitating transportation and storage. Government of Pakistan intends to bring LNG as a substitute to diminish the supply demand gap of CNG.[21]The idea to import LNG for Pakistan energy sector was firstly proposed in 2005 National Energy plan. However, idea was not materialized due to OGRA rejection and interference of Supreme Court in fixing the increased prices of CNG .[22] Present Pakistan Qatar Government to Government LNG contract that was dealt by PM Abbasi had settled in 2015 .The validity period of contract is 15 years with annual 3.75 million tons supply of LNG. Government officials consider the projects of LNG as a major breakthrough for energy sector. However, antagonist factions strongly oppose the LNG import projects due to high prices and chances of corruption. [23] The projects of LNG are still underway and no final verdict can be made without observing ground realities after inclusion of LNG in Pakistan energy sector.

\subsection{Liquefied Petroleum Gas (LPG)}

Liquefied Petroleum Gas is another environmental friendly fuel source. The use of LPG in areas where wood is used as fuel source also decreases the rate of deforestation. LPG is mainly used in residential, automotive and commercial sector. Although the contribution of LPG in Pakistan power mix is relatively low $2.6 \mathrm{~kg}$ per capita.[24] However, the consumption of LPG in world is high with USA, Mexico and Japan as 
major consumer states [25] In Pakistan LPG is mostly used in ruler areas where natural gas is not accessible. The progress in LPG sector is very slow with around only ten of LPG producers. The few producers results in low market competition and thus formation of cartel. [26]The LPG cartel monopolizes the market that results in high prices of LPG. Pakistan is leading south Asian countries with highest LPG rates in region. The major consumer of LPG in Pakistan is mainly households. However, the high prices of LPG leave no options for low income citizens but resort to the option of cutting of forests for fuel.

\subsection{Coal}

Pakistan is blessed with plentiful coal endowments. The country has proven coal reserves of 186 billion tons .Out of which tremendous reserves of 175 billion are in the Thar region .The history of coal as a fuel source can be traced back to industrial revolution. The contribution of coal in success of industrial revolution cannot be denied. [27] Coal is still utilizes as a major source for power generation in many European countries. Almost 40 percent of world electricity is generated from coal. China produces 53 percent of its electric power from coal while India generates 67 percent of power from coal. However, in Pakistan the use of coal as power generation source is negligible. Pakistan's Thar coal is renowned from four decades but its share in energy is negligible. There are three pre conditions to check the viability of energy source, its affordability, its accessibility and its capability for continuous supply. Pakistan's coal reserves fulfill this criterion of sustainability. Pakistan's coal despite meeting the criteria is playing a negligible role in total energy mix. [28]

According to energy security plan of 2005 Pakistan will generate 25000 MW by utilizing Thar coal. Today coal is widely deplored due to environmental considerations. However, it is still used as a major source of electricity generation in world .Pakistan's coal is still not properly utilized in energy scarce county. The reason is high infrastructural cost, lack of technological availability and specialty, political discontentment and crisis of skilled human resource. Pakistan has started work with cooperation of china under CPEC projects. But the dilemma is that Pakistan is importing coal for most of its coal power projects rather than utilizing its indigenous coal reserves.

The transformation from imported oil to imported coal will not resolve Pakistan's balance of payment issue. Pakistan should keep in mind increase in price of coal from 75 USD to 150 per ton when oil prices hiked in 2008 and slapping taxes imposed by India and Indonesia on coal export prices .There are some myth attached with Thar coal that it cannot be transported due to high combustion volatility. However same coal is transported in India to distances of hundreds KMs. Pakistan is still using conventional method of shovel and truck for coal mining that takes more time and energy. Currently two coal power plants installed outside Thar are enough to meet instant need others projects should be installed in Thar. Pakistan must use indigenous coal for achieving energy security in energy scarce country. The import of coal when country own coal is equivalent to oil reserves of Iran and Saudi Arabia is nothing but drawback in policy formulation.

The vast deposits of Thar coal can be utilized by exporting coal to India it can be exported to Indian Rajistan region that is adjacent to Thar region of Pakistan. Pakistan can also get expertise from India to utilize Thar coal as India has great experience in power generation from coal and third unique option can be revival of barter economy that will serve the interests of both states. Pakistan provides coal to India and India in return provides electricity to Pakistan by placing coal based power plants in its border areas. [29]

\subsection{Renewable Sources of Energy}

The change of millennia has also changed the conventional sources of acquiring energy. The worldwide increasing demand of energy has increased the gap between demand and supply of energy. The excessive use of expensive thermal sources, rapid pace depletion of these sources and environmental considerations attached with them forced the world to explore sustainable and reliable sources for energy generation. Therefore globally there is worldwide increasing trend to adopt renewable energy sources for fulfilling energy demand. However, Pakistan energy mix is still in favor of thermal to great extent. [30] The share of renewable is only 1.4 percent in Pakistan's energy mix.

\subsection{Hydel}

Pakistan has potential of generation of 50,000 MW of electricity from Hydel sources. However the current installed hydel capacity is of $6902 \mathrm{MW}$ only. According to the data provided in Energy yearbook (2016) share of hydel in Pakistan energy mix is 31.1 percent. Whilst the share of hydel in 80s was about 60-67 percent .Pakistan suffers heavily from overflowing rivers in every moon soon season. These overflowing rivers can play a role of blessing in disguise if country uses proper mechanism. The construction of dams can not only rescue country from floods it can also produce adequate energy to overcome electricity shortfall. [31] This region has the option of exploiting water reserves flowing from Arabian Sea to Himalayas. Pakistan in early years of its independence used the potential of hydel power for fulfilling its energy demand. Mangla was first major developmental project that was completed in 1967 with capacity of generating 1000MW. Subsequently Tarbela with capacity of 3,478 had been completed in 1976. Ghazi Barotha was another 
development with capacity of 1,450 MW. However, after these three major developments the unfortunate era of politicization of water started that halted further progress in hydel energy. [32] The controversy and conflicts over Kala Bagh dam halted development in other hydel power projects also. However, in recent years some progress had been made in hydel 36 power projects. The work on various projects has been started and many of these projects are estimated to be completed in 2018.

Chairman WAPDA in an interview to anchor Kamran Shaid in programme on the front at dunya news gave the deadline for completion of Nelum Jhelum hydel power project in somewhere between May to July 2018. He considered Nelum Jhelum with capacity of 968 megawatt as major breakthrough in energy mix and he determined this project with other projects that will be completed in 2018 will end load shedding in country.

\subsection{Nuclear Source of Energy}

The use of nuclear energy for generating power was started in 1950s.Today there are around 440 nuclear reactors operating in world with combine capacity of 39,000 MW. Pakistan generates around 1, 030 MW electricity from nuclear sources .[33] Currently there are four nuclear power plants (CHASHNUPP- 1 , CHASHNUPP 2 , CHASHNUPP 3 and KANUPP 1) operating in country. The work on KANUPP-2, KANUPP-3 and CHASHNUPP -4 is in progress. [34] The contribution of nuclear in Pakistan energy mix during FY 2016 was $4.1 \%$ only (Energy Year Book 2016). Pakistan atomic energy commission (PAEC) aimed to enhance it to 8800 MW till 2030. Nuclear is viable option for energy deficient country like Pakistan. As one pound of Uranium can substitute 2, 55,000 of oil gallons, natural gas of around $40,000,000$ cubic feet and 1,500 tons of coal. Pakistan is strictly observing the bindings of IAEA for its nuclear power generation. [35] It has also applied for nuclear supplier group (NSG) membership that can help Pakistan remarkably in increasing the share of nuclear in its energy mix.

\subsection{Solar Energy}

Pakistan is blessed with plentiful solar energy with availability of sun around 330 days in year. [36] However the contribution of solar in Pakistan's current energy mix is meager. Solar is sustainable, clean, reliable and all of above indigenously available option for Pakistan increasing energy demand. For plenty of reasons exploiting solar energy is suitable option for overcoming energy crisis in Pakistan. A large number of our population lives in rural areas where electricity is not available. To provide electricity through national grid lines to these villages will, need long term planning, development of infrastructure and large-scale investment. However, to provide them solar panel will be a more feasible option. In most of villages where natural gas is not available people use wood as a fuel source. The use of solar cooker for cooking can control increasing deforestation rate. The solar energy can be best utilize in rural areas of Sindh and Baluchistan. In most of villages where electricity is not available and people live in one room house. Their energy demand is maximum 100 watt that can be best served by using solar power. [37] The solar power plants of 20-50 megawatts are spread throughout the state. Although development towards Solar is slow but it can get better in future with more efforts and efficiency.

\subsection{Wind}

Pakistan is capable of generating 50,000 MW of energy from wind. The combine capacity of solar and wind can generate 300,000MW of electricity. Currently Pakistan has installed wind energy capacity of 356 MW. Different researchers indicate Pakistan has best corridors of wind in regions of Thatta, Islamabad and Karachi. The installation of wind turbines in these areas can mitigate the energy deficiency of Pakistan. Wind is environmental friendly source of energy. Many countries in world including our neighbor state India are making the best use of it. Pakistan is also ambitious to increase the share of wind energy in its energy mix. However, progress on ground is very slow but it can be improved by installing more wind turbines in its perfect wind corridors. [38]

\section{Challenges of Pakistan's Power Sector}

Pakistan is facing protracted energy crisis that not only jeopardize country's economy but also haul sustainable development. The shortfall of energy is due to shortfall in governance and shortfall in political will rather than a shortfall of supply. [39]

\subsection{Fragmented Governance Structure}

The fragmented governance structure of Pakistan's energy sector itself is a major challenge. This fragmented institutional structure and absence of cohesive body to deal with energy issues slow down the policy implementation process as well as it incurs additional transaction cost. [40] Currently there are six ministries and 42 agencies working for energy developmental projects in country.

Each entity is working under its own term of reference (TOR) and strategies. The absence of a united body and lack of coordination among these governing entities at different level makes the sector dysfunctional. Moreover, the political appointments rather than prioritizing experts and professionals on important positions in energy deficient country is also a serious concern and major cause 
of consistent energy crisis.

\subsection{Inefficient Regulatory Framework}

The two regulatory authorities of energy sector have been put under ministerial control in June 2017. NEPRA has been placed under the command of water and power division and OGRA has been placed under the command of Petroleum and natural resource division. [41] The aim of formulating regulatory bodies for energy sector was to improve efficiency and serving investors and customer interest independently. However, these regulatory authorities are working in highly centralized manner under considerable political influence on pricing and tariffs.

The pricing and tariffs related decisions of these regulatory authorities need approval of Government. The organogram of NEPRA consist of a chairman and one member from each province; all these crucial appointments are made by Government where political affiliation is preferred rather than expertise. Due to delays in appointment sometime NEPRA works in absence of chairman (2002-3) and sometimes it works without members (2005). [42] . Hence both regulatory authorities NEPRA and OGRA face shortage of professional capacity to monitor regulatory framework efficiently. Moreover, the lack of collaboration between OGRA and NEPRA also creates disharmony in pricing of electricity and gas that gives inconspicuous message to investors. [43]

\subsection{Federal - Provincial Issues on Energy Sector}

The harmony between federating units and center is important for the national development as well as for fostering sectoral performance. Unfortunately, Pakistan since its inception is facing tensions between center and provinces over various issues. Even after the 18th amendment in constitution the tension between center and provinces persist in one form or another. The center-province tension over energy related issues is ongoing. Mostly the tension is over the issues of hydroelectric projects or resource distribution and provinces demand for due share. The provincial grievance over Kalabagh Dam is a prime example in this regard. Therefore, it is necessary to take certain measures for resolving center-province issues for smooth operation of power projects.

\subsection{Independent Power Producers (IPPS)}

The major policy decision of introducing IPPS in energy sector although inexorable but induced considerable implications on power sector. The prices of power raised and Pakistan energy mix shifted highly in favor of oil. The rise in electricity price was not only due to excessive use of oil for power generation but due to inexpedient agreements. These imprudently signed agreements not only allowed
IPPS to set high tariffs but also provided them inessential guarantees. [44] Resultantly to manage increasing prices Government subsidized the tariff for certain consumers that resulted in other financial issues.

\subsection{Transmission and Distribution Losses}

The power generated in power house reaches to end users through different transmission and distribution lines, cables and transformers. When electricity generated in power station doesn't match with electricity reached to end users that difference between the generation and distribution is called Transmission and distribution loss.[45] It is estimated that T\&D loss of one percent incurs deficit of one billion over national treasury. However, Pakistan ranks 14 out of 131 countries of world in T\&D losses. These T\& D losses are either technical or nontechnical/commercial. Technical issues include outdated technology, leakage, inefficiency in transmission and flawed planning plus poor design of network of distribution. Non-technical issues include Corruption, pilferage, illegitimate connections, defective meters and nonpayment of electric bills. Both technical and non-technical issues arise due to maladministration and poor governance. PESCO and SEPCO have shown poor performance in T\&D losses with reported losses of 34.8 and 27.5 percent respectively. The performance of other distributive companies is also disappointing. The only option left to reduce these line losses is to disconnect the transformers where unidentifiable defaulters found. [46] There is dire need of taking urgent measures to control these losses. Otherwise it will bring devastating consequences for already deteriorating energy sector.

\subsection{Undue Subsidies}

The imbalance between electricity price per unit and per unit cost of supply indicates the level of subsidy. Pakistan's government pay subsidies in billions for electric power consumer, consequently it is indebted in billions of circular debt. The objective behind providing subsidy on electricity tariff was to increase lifeline (indigent) consumer capacity of paying electricity bills. Pakistan adopted the incremental block tariff (IBT) strategy for poor consumers. In block tariff pricing the charges of electricity increase with the increase in use of unit. In IBT if a consumer pay 2.9RS per KWh for the first $100 \mathrm{KWh}$, then it will charge 3.9 RS until 300KWh, then 5.49 till $700 \mathrm{KWh}$ and after this limit it will charge 6.90 for the levels above. There is an unreasonable tariff of 75RS for minimum use of Electricity that obviously affect the poor household who uses electricity only for lightening house. Despite paying heavy subsidies for helping the poor households, the major portion of these subsidies benefits richest households in country. The direct transfer system as in Benazir Income Support programme can be more cost effective and specific in achieving the 
target.[47] There is need to introduce effective policy options for achieving target Otherwise Pakistan will not ever able to get rid of energy crisis.

\subsection{The Problem of Circular Debt}

Circular debt chain starts from electricity consumers who don't pay their electricity bills and ends at Government nonpayment of money to power sector entities.[47] When government withholds the payment of an entity in turn it withholds the due payment to next actor in chain and so on. This is the whole story of circulating circular debt of Pakistan's power sector. Although in 2013 government claimed that they cleared the debt of 480 billion rupees. However, presently Pakistan's circular debt has reached beyond 800 billion rupees compare to 685 billion rupees about a year ago.[48] Some analysts are of the view that circular debt actually is a real monster behind the energy crisis .Other believes that maladministration, bad governance and corruption are more important. The inefficient governance is responsible for circular debt from corporate to sector level. The ineffective government policies, failure to recover T\&D losses, overstaffing rather than few and specialized task force, delays in payments, inefficiency in collection of revenue, delays in determining tariff and inappropriate allocation of subsidies are issues of paramount importance that are responsible for lingered circular debt in country .[49] The prerequisite to resolve energy crisis is to address the issue of circular debt on a war footing.

\section{Policy Issues}

\subsection{Overambitious and Ambiguous Policy}

In policy making process one need to be realistic and don't need to be ambitious. There is no need to give policy with tall objectives and tall promises. When these promises not achieve then policy lead to the failure. Therefore, the failure policy either leads to termination or work as failed policy. Termination of policy is costly step for the government to take. Because, there are a lot of stakes of resources, jobs and institutions. When policy is not able to be modify due to lack of skill analysis or need analysis then these things effects power sector badly.

There exists information gap between policy planners and society which results in bad policy decisions. When policies are devised by people who are unable to understand the demands and needs of the policy subjects then in result inefficient and ambiguous policy comes in effect.[50] Moreover, the overambitious nature of the policies without evaluating the resource affordability and societal structure make the policy fail to attain desired outcomes. If a policy comes that is not implementable which is apart from ground realities or practical situation.
A policy which is not corresponding to the capacity of implementers, of the bureaucracy, of the administrative machinery and of the resources. It means that something is wrong with that policy formulation.

\subsection{Poor Governance Structure}

The poor governance structure, maladministration and corruption hamper the implementation of policies. The major reason behind poor governance structure is lack of collaboration to achieve certain policy objectives. The lack of collaboration among centre and provinces and among provinces and localities hinders the policy implementation process.[51]The success of energy policies depends on the joint efforts of all actors at centre, provincial and local level. The issue of corruption and maladministration also hamper the policy implementation process as the office holders put the national interests at stake and keep their self-interest on priority.

\subsection{Lack of Resources}

For the success of any policy the availability of resources is very crucial whether it is technical, financial or human resource.[51]The lack of resources is major hindrance in power policies of Pakistan. All the policies are well formulated and desire to achieve the energy efficiency in country however limited resources mitigate the success rate of these policies. Due to the lack of financial resource there is inadequate infrastructural development and inability to solve the circular debt issue of Pakistan. The scarcity of technical and human resource hinders the developmental process for attaining progress. Moreover, the misuse of resources is also alarming like appointing a misfit person at higher position effects the formulation and implementation of policy .The person without relevant expertise and experience cannot tackle the policy issues like an experienced and expert one. The misuse of financial resources leads to corruption and fraud cases which again badly effect the implementation of policy decisions.

\subsection{Lack of Political Will and Interest}

The interest and will of ruling body is necessary for any developmental project. In Pakistan national politics has become a blame game where every party is blaming other for inefficiency and incompetency. The political economy of formulating policy has become vote oriented rather than welfare oriented policies.[52] The public representatives are more inclined to increase their vote bank rather than initiating and supporting long term public welfare programs. In Pakistan another policy dilemma is that every new elected government discontinues the policies and projects of the previous governments. The political parties tends to introduce policies that bring more benefits for their favorites and increase the chances for them to be re -elected. 
[53] This lack of will and interest of political representatives bring difficulties in attaining the power policy goals. That's why today Pakistan is facing grave crisis of energy that is worsening on every coming day.

\section{Policy Options for Pakistan}

\subsection{Diversification of Energy Mix}

Pakistan is heavily reliant on imported energy sources specifically oil for fulfilling most of its energy demand. The rapid depletion of these traditional energy sources and Pakistan own economic condition demand the diversification of its energy mix. There is instant need to expedite diversification process for economic sustainability and societal progression. Otherwise, Pakistan will remain far behind in world of rapidly growing economies.

\subsection{Utilization of Indigenous Sources of Energy}

Unfortunately, Pakistan is energy deficient country but despite having sufficient natural endowments. It is blessed with enough resources to generate its own energy for fulfilling the energy demand of its population. Coal is still use as a major source of power generation in world and Pakistan has the estimated coal reserves of 186 billion tons lying dormant. Furthermore, the renewable power generation capability of Pakistan is also enough for satisfying the demand. The exploration of oil and gas plus utilization of coal and available renewable sources of energy have not only capacity of fulfilling the demand, but have capability to produce excessive energy for Pakistan.

The utilization of domestic sources of energy was the major focus of power policy 2013. However due to gaps in implementation Pakistan failed to achieve this goal. As the coal use for power projects is mostly imported regardless of vast coal reserves in country. The transformation from imported oil to imported coal will not resolve Pakistan balance of payment issue. Pakistan should keep in mind increase in price of coal from 75 USD to 150 per ton when oil prices hiked in 2008 and slapping taxes imposed by India and Indonesia on coal export prices.

The vast deposits of Thar coal can be utilized by exporting coal to India it can be exported to Indian Rajistan region that is adjacent to Thar region of Pakistan. Pakistan can also get expertise from India to utilize Thar coal as India has great experience in power generation from coal and another unique option can be revival of barter economy that will serve the interests of both states. Pakistan can provide coal to India and India in return can provide electricity to Pakistan by placing coal-based power plants in its border areas. [54]

There is dire need to exploit the available renewable energy sources for overcoming the energy crisis and environmental degradation. The whole world is not only supporting renewable but major powers are also providing funds for development of renewable projects. Pakistan can utilize hydel, solar, wind, and biomass sources for producing renewable energy. Pakistan can encourage the use of renewable by providing feed in tariffs and incentives on starting a renewable energy project. Hydel is the cheapest source of energy for Pakistan. In short run Pakistan can start mini hydro projects for electrifying the villages and small communities. In long run it is needed to construct the dams by resolving all the federal -provinces differences and discontentment.

For plenty of reasons exploiting solar energy is suitable option for overcoming energy crisis in Pakistan. A large number of our population lives in rural areas where electricity is not available. To provide electricity through national grid lines to these villages will need long term planning, development of infrastructure and large-scale investment. However, to provide them solar panel will be a more feasible option. The solar energy can be best utilized in rural areas of Sindh and Baluchistan. In most of villages where electricity is not available and people lives in one room house. Their energy demand is maximum 100 watt that can be best served by using solar power. [55]

\subsection{Energy Conservation}

The growing energy consumption, depleting energy resources and escalating energy crisis demand the conservation of energy. It is the duty of government and citizens to promote energy conservation culture. In Pakistan the trend of wearing three piece suits in chilled rooms have become popular regardless of outside temperature may cross 40 degree. There is dire need to start public awareness campaigns for conservation of Energy. The promotion of energy efficient devices like air conditioners, energy saving bulbs, ovens, washing machine etc. is required. Furthermore, the labeling of energy consuming devices can also contribute in bringing energy efficiency. [56]

However, it is not always money that makes sense but to motivate people socially and religiously can bring more impressive outcomes. To aware people religiously many ahadits and ayahs of Quran can be quoted where extravagance is condemned either it is money, food, water or any other thing. Quran says:

The spendthrifts are the brothers of the shayatin and the shaitan is ever ungrateful to his Lord. (Al Quran, Surah Isra, verse 27).

Moreover, there are number of social campaigns in world that were targeted to bring energy efficiency by promoting energy conservation culture. The Go cold Turkey campaign targeted students and drive them to make promise that they will turn off the unnecessary electronic appliances. Then there are numerous campaigns launched in Korea for energy conservation that were very success. 
[57] Pakistan can also start these sorts of campaigns to bring awareness in public to promote the culture of energy conservation. Universities and think tanks can play an effective role in developing an energy conservation culture.

\subsection{Economic Options}

The energy crisis of Pakistan and the connected issue of circular debt are aggravated since last few years. Pakistan's circular debt has reached beyond 800 billion rupees compare to 685 billion rupees about a year ago. [58] The inefficiencies in collection of bills, expensive fuel and government inability to pay subsidies have escalated the circular debt issue. The nonpayment of electricity subsidies is primary cause of circular debt problem. The subsidy system of Pakistan is ineffective as it has proved more advantageous for richest segments of society rather than helping the needy and poor. To provide the subsidies to all electricity consumers increases the financial burden of government. Thus, replacing subsidy with cash transfer programme like BISP can be more fruitful and financially viable option for Pakistan. An example of successfully replacing subsidy with cash transfer is Iran. Pakistan can learn from Iran how it successfully replaced subsidy with the cash transfer programme. [59]

Moreover, the nonpayment of electricity bills is another financial obstacle for the sector. Pakistan can switch to the key meter and bill meter technology to overcome this issue. The prepaid billing technique can be used for consumers who are irresponsible towards paying their bills and postpaid billing for those who pay their bills regularly. Then in long run the induction of smart meters can also help in conserving energy and bringing transparency. It will enable customer to monitor the impacts of their lifestyle on energy consumption. Furthermore, it will increase accuracy on both consumer and supplier ends. [60]

\subsection{Demand Management}

In Pakistan the shortage of electricity is not due to shortage of installed capacity but due to shortfall in generating capacity. Pakistan has enough installed capacity to satisfy the electricity demand. The inefficiencies in governance, lack of infrastructure or outdated infrastructure, issue of circular debt, T\&D losses are the major cause of power crisis. Thus, it is needed to improve governance structure by encouraging merit system and discouraging corruption and inefficiencies. The infrastructural development is mandatory to bring efficiency in power generation and to reduce T\&D losses. To make the electricity transmission possible to the end consumer Pakistan need automatic metering system (ARM) that will eliminate theft and human involvement. On long term it needs renewable energy so that to have sustained and diverse energy mix.

\subsection{Development of Human Resource}

Human resource is an important key to development if organize and employ efficiently. It is next to capital and land in factor of production. [61] However, unfortunately in Pakistan the employment of inefficient and irrelevant persons at higher positions has deteriorated the sector performance. Furthermore, we lack human resource in Engineering of certain projects. Thus, it is needed to encourage youth to get education and training in relevant areas by opening the relevant department in various universities. Furthermore, we need to say good bye to culture corruption for the sake of bringing efficiency and development.

\section{Conclusions}

The rapid growth in world population, technological innovation and overconsumption of energy has created energy deficiency in the world. Today, States are worried for the increasing demand and supply gap of energy. The utilization of indigenous sources is prerequisite to bring energy sufficiency in the country. The over utilization of expensive imported resources has already deteriorated the energy situation. Pakistan cannot ever satisfy its energy demand without utilizing the domestic renewable energy resources. The diversification of the energy mix and utilization of indigenous resources is only option remain with Pakistan to get rid of lingering energy crisis. The overreliance on expensive imported sources has created balance of payment crisis and circular debt issue in Pakistan. Moreover, the environmental concern attached with the traditional sources of energy also demands the transformation of the energy mix. Globally there is already large-scale diversification towards renewable and indigenous sources of energy.

Although Pakistan has comprehensive set of policies and numerous sectoral entities but still it is unable to resolve the issue of hours long power outages. The energy crisis of Pakistan is result of multiple factors. The culture of rent seeking, corruption, poor governance, institutional inefficiency, electricity theft and circular debt are responsible factors for growing energy crisis in Pakistan. That's why despite having enough resources and capacity country is unable to satisfy the energy demand of its population. It is required to resolve these issues instantly to get rid of this anomalous crisis of energy.

Another major factor of energy crisis is that Pakistan didn't create any awareness to conserve energy. It is not about the price a consumer pay for consuming energy but the point is that they are consuming the energy of other person share. Pakistan needs to develop Energy conservation culture, a unit saved is much cheaper than a unit generated. So, if that is known by the consumer it will have effect on the usage of energy. On other side the consumption pattern of the electric appliances has been 
changed so drastically that now all the appliances at home needs more energy. People should be aware about the advantages of energy efficiency and energy efficient devices labeling of devices is necessary as it will develop more responsible attitude. It is political leadership who has to take this issue on high political agenda to bring it to the top most priority of the country. For individuals in the society to act in this manner and for conservation of energy, from water to electricity and oil, there is need of a comprehensive approach for the massive awareness. It is the duty of each and every person to give their due share in resolving this energy crisis. Almost unquestionably, energy has become a serious concern for survival on this blue-green planet.

\section{REFERENCES}

[1] Faheem, J. B. (2016). Energy crisis in Pakistan. IRA-International Journal of Technology \& Engineering, 03 (01), 1-2. Retrieved from https://research-advances.org/inde x.php/IRAJTE/article/view/95/109

[2] Qureshi, M. N. (2009). Energy crisis in Pakistan: A threat to national security. ISSRA papers, I, 72-101.Retrieved from http://www.ndu.edu.pk/issra/issra_pub/articles/issrapaper/I SSRA-Paper-Vol-I-2009/ISSRA_papers_Vol_I_2009.pdf

[3] Hasan, M. H. 2013. “An Overview of Pakistan's Energy Sector.” Solutions for Energy Crisis in Pakistan I: 5-20.

[4] Sethi, N. 2015. "Power Sector Reforms: Pakistan's Energy Crisis and Ways Forward." In Pakistan's Interminable Energy Crisis: Is there any way out, edited by M. Kugelman, 119-133. Wilson center.

[5] Kugelman, M. 2015. "Easing an Energy Crisis that Won't End.” In Pakistan's Interminable Energy Crisis: Is There any Way Out?, edited by M. Kugelman, 1-22. Wilson Center.

[6] Mirjat, N. H., Uqaili, M. A., Harijan, K., Valasai, G. D., Shaikh, F., \& Waris, M. 2017. "A Review of Energy and Power Planning and Policies of Pakistan.” Renewable and Sustainable Energy Reviews 79:110-127.https://ideas.repec .org/a/eee/rensus/v79y2017icp110-127.html

[7] Ali, A. 2013. Issues in Energy Policy. Charleston, SC, USA: CreateSpace.

[8] Mahmood, A. 2015: Implementation of National Energy Policy.” Solutions for Energy Crisis in Pakistan II: 32-55.

[9] Iqbal, K., \& Hussain, A. 2015. "Solutions for Energy Crisis in Pakistan.” Solutions for Energy Crisis in Pakistan, II: 10-18.

[10] Hasan, M. H. 2013. “An Overview of Pakistan's Energy Sector.” Solutions for Energy Crisis in Pakistan I: 5-20.

[11] Ali, A. 2013. Issues in Energy Policy. Charleston, SC, USA: CreateSpace.

[12] Hussain, M. B. 2013. "Role of Universities and Think Tanks In Energy Conservation In Pakistan. ” Solutions for Energy
Crisis in Pakistan, II: 145-167.

[13] Luft G. \& Korin A. (2009). Energy security challenges for the 21st Century. USA: Green wood publishing group.

[14] Government of Pakistan. Ministry of Finance. (2016-17). Pakistan Economic survey. Islamabad: Finance Ministry.

[15] Ali, S. A. (2017). Pakistan's energy issues: Success \& challenges. Charleston, SC, USA: CreateSpace.

[16] Government of Pakistan. Ministry of Finance.(2016-17). Pakistan Economic survey. Islamabad: Finance Ministry.

[17] Bymap. (2017, February 02). Natural gas consumption. Retrieved January 05, 2018, from Bymaap: http://world.bymap.org/NaturalGasConsumption.html

[18] Energy scenario in Pakistan. (2013). Karachi, Pakistan: KCCI.

[19] Government of Pakistan. Ministry of finance.(2012-13). Energy.

[20] Raza, H. A. (n.d.).Development of CNG industry in Pakistan .Retrieved January 11, 2018, from http://www.gee-21.org/publications/Development-of-CNGIndustry-in-Pakistan.pdf

[21] Ali, A. (2013). Issues in energy policy. Charleston, SC, USA: CreateSpace.

[22] Malik, A. (2013). Tackling the energy crisis. In R. Amjad, \& S. J. Burki (Eds.), Moving the economy forward (pp. 133-150). Lahore school of economics.

[23] Ali, S. A. (2017). Pakistan's energy issues: Success \& challenges. Charleston, SC, USA: CreateSpace.

[24] Ali, A. (2013). Issues in energy policy. Charleston, SC, USA: CreateSpace.

[25] The Global Economy. (2014). LPG consumption - country rankings. Retrieved January 06, 2018, from The global economy.com: http://www.theglobaleconomy.com/rankings /lpg_consumption/

[26] Ali, A. (2013). Issues in energy policy. Charleston, SC, USA: CreateSpace.

[27] Wilde, R. (2018, January 18). Coal in the Industrial Revolution Retrieved February 04, 2018, from thoughtco.com:https://www.thoughtco.com/coal-in-the-indu strial-revolution-1221634

[28] Mansoor, K. (2015). How coal can help address Pakistan's energy crisis. In M. Kugelman, Pakistan's interminable energy crisis: is there any way out? (pp. 40-52). The Woodro Wilson Center.

[29] Ali, A. (2013). Issues in energy policy. harleston, SC, USA: CreateSpace.

[30] Khan, N. A., Mirza, I. A., \& Khalil, M. S. (2005). Renewable energy in Pakistan: Status and trends. akistan Alternative Energy Development Board, 2005

[31] Shehzad, M. (2013). Hydroelectric power is the cheapest option. The Friday Times.

[32] Muzamil, H. (2015, October 04). Pakistan's energy mix: ower and politics. The daily Dawn. 
[33] World Nuclear Association. (2018). Nuclear power in the world today. etrieved January 08, 2018, from http://www.w orld-nuclear.org/information-library/current-and-future-gen eration/nuclear-power-in-the-world-today.aspx

[34] The Nation. (2017, September 08). Retrieved January 08, 2018, from https://nation.com.pk/08-Sep-2017/pm-abbasi-t o-inaugurate-340mw-c-4-nuclear-power-plant-at-chashma

[35] Jaspal, Z. N. (2017). Nuclear power generation. Retrieved January 07, 2018, from Pakistan Observer: https://pakobserver.net/nuclear-power-generation/

[36] Shehzad, M. (2013). Hydroelectric power is the cheapest option. The Friday Times.

[37] Khan, N. A., Mirza, I. A., \& Khalil, M. S. (2005). Renewable energy in Pakistan: Status and trends. Retrieved January 08, 2018, from http://atrc.net.pk/resources/pakistan/renewable energy/renewable_energy_pakistan_status_and_trends.pdf

[38] Latif, A., \&Ramzan, N. (2014). A Review of Renewable Energy Resources in Pakistan. Journal of Global Innovation in Agricultural and Social Sciences, 129-130.

[39] Kugelman, M. 2013, “Pakistan's Energy Crisis from Conundrum to Catastrophe”. http://nbr.org/downloads/pdfs /eta/Kugelman_commentary_03132013.pdf

[40] SDPI. 2013. "Pakistan Energy Sector Appraisal." https://www.sdpi.org/publications/files/Draft\%20Report\%2 0-\%20Energy\%20Sector\%20Appraisal.pdf

[41] Hali, S. M. 2017. "Regulatory Bodies Placed Under Ministries.” Pakistan Observer, March 06. https://pakobserver.net/regulatory-bodies-placed-ministries

[42] Malik, A. (2007). Effectiveness of regulatory structure in the power sector of Pakistan. Islamabad: Pakistan Institute of Development Economics. Retrieved from http://www.pide. org.pk/pdf/Working\%20Paper/WorkingPaper-25.pdf

[43] The planning commission of Pakistan. (2013, March). The Causes and impacts of power sector circular debt in Pakistan. March 08, 2018.

[44] Hasan, M. H. 2013. “An Overview of Pakistan's Energy Sector.” Solutions for Energy Crisis in Pakistan I: 5-20.

[45] Jiguparmar. 2013. “Total Losses in Power Distribution and Transmission Lines.” http://electrical-engineering-portal.co $\mathrm{m} /$ total-losses-in-power-distribution-and-transmission-lines $-1$

[46] Ali, S. A. (2017). Pakistan's energy issues: Success \& challenges. Charleston, SC, USA: CreateSpace.

[47] Trimble, C., Yoshida, N., \& Saqib, M.. 2011. Rethinking Electricity Tariffs and Subsidies in Pakistan. The World Bank.

[48] Kiani K. (2017, August 08). Circular debt touches Rs800bn: Pepco. Retrieved march 09, 2018, from https://www.dawn.com/news/1350245

[49] The planning commission of Pakistan. (2013, March). The Causes and impacts of power sector circular debt in Pakistan. March 08, 2018

[50] Asghar, M. U. 2013. "Governance Issues in Pakistan: Suggested action strategy.” ISSRA Papers 5(I): 113-134.
[51] Ali, S. (2006). Why does policy fail? Understanding the problems of policy implementation in Administration, 34 (1). Retrieved from https://pdfs.semanticscholar.org/3ea7/c1c16 06abdd5bb0ea220183ac1ae3df9a9c2.pdf. Pakistan - a Neuro-cognitive Perspective. International Studies in Educational

[52] Toru, S. K. 2015, "Development Policy Failure in Pakistan. Southern Voice on Post -MDG International Development Goals. "http://southernvoice.org/wp-content/uploads/2015/ 02/SV-OP-19.pdf

[53] Ali, S. (2006). Why does policy fail? Understanding the problems of policy implementation in Administration, 34 (1). Retrieved from https://pdfs.semanticscholar.org/3ea7/c1c16 06abdd5bb0ea220183ac1ae3df9a9c2.pdf. Pakistan - a Neuro-cognitive Perspective. International Studies in Educational

[54] Ali, A. (2013). Issues in energy policy. Charleston, SC, USA: CreateSpace.

[55] Khan, N. A., Mirza, I. A., \& Khalil, M. S. 2005. "Renewable Energy in Pakistan: Status and Trends." http://atrc.net.pk/resources/pakistan/renewable_energy/rene wable_energy_pakistan_status_and_trends.pdf

[56] Ali, S. A. 2015. "Issues in Energy Policy.” Solutions for Energy Crisis in Pakistan II: 95-190.

[57] Hee, K. K. 2007. "Overview on Public Benefit Campaigns to Promote Energy Conservation and Energy Efficiency." https://sustainabledevelopment.un.org/content/documents/1 477background2.pdf

[58] Kiani, K. (2017, August 08). Circular debt touches Rs800bn: Pepco. Retrieved march 09, 2018, from https://www.dawn.com/news/1350245

[59] Trimble, C., Yoshida, N., \& Saqib, M.. 2011. Rethinking Electricity Tariffs and Subsidies in Pakistan. The World Bank.

[60] Shabbir, H. (2017, October). Smart meters in Pakistan: A technological perspective. Retrieved April 28, 2018, from https://propakistani.pk/problog/smart-meters-technological perspective/

[61] Hassan, B. 2014. “Need for Human Resource Management.” Pakistan Today, April 29.https://www.pakistantoday.com.p k/2014/11/01/need-for-human-resource-management/ 